\title{
That Which is Essential has been Made Invisible: The Need to Bring a Structural Risk Perspective to Reduce Racial Disproportionality in Child Welfare
}

\author{
Megan Feely ${ }^{1}$ [ Emily Adlin Bosk ${ }^{2}$
}

Accepted: 12 January 2021 / Published online: 21 February 2021

(c) Springer Science+Business Media, LLC, part of Springer Nature 2021

\begin{abstract}
The racial and ethnic disproportionality and disparity in the child protective system (CPS) has been a concern for decades. Structural factors strongly influence engagement with the child welfare system and families experiencing poverty or financial hardship are at a heightened risk. The economic factors influencing child welfare involvement are further complicated by structural racism which has resulted in a greater prevalence of poverty and financial hardship for families who are Black, Native American or Alaska Native (Indigenous), or and Latino/Hispanic (Latino) and their communities. The multiple decision points within CPS are an opportunity to reify or correct for bias in child welfare outcomes. One major effort to eliminate racial disparities and disproportionalities has been to enact standardized decision-making procedures that aim to control for implicit or explicit bias in CPS. The Structured Decision-Making Model's (SDM) actuarial-based risk assessment (RA) is the gold-standard of these efforts. In this conceptual article, we ask (1) How are structural factors accounted for in assessment of risk within CPS? and (2) What are the consequences when structural factors are left out of risk assessments procedures? We posit that the exclusion of race, ethnicity, and economic factors from the RA has inflated the importance of variables that become proxies for these factors, resulting in inaccurate assessments of risk. The construction of this tool reflects how structural racism has been overlooked as an important cause of disproportionality in CPS, with interventions then focused on individual workers and cases, rather than the system at large. We suggest a new framework for thinking about risk, the structural risk perspective, and call for a revisioning of assessment of risk within child welfare that acknowledges the social determinants of CPS involvement.
\end{abstract}

Keywords Disproportionality $\cdot$ Disparities $\cdot$ Structural racism $\cdot$ Socioeconomic disadvantage $\cdot$ Algorithms $\cdot$ Actuarial-based risk assessment $\cdot$ Decision-making

\section{Introduction}

Child welfare decision-making is a high-stakes task. When decisions about whether child maltreatment has taken place are incorrect children left in homes who should have been

This manuscript was equally authored.

Megan Feely

Megan.feely@uconn.edu

Emily Adlin Bosk

emily.bosk@ssw.rutgers.edu

1 School of Social Work, University of Connecticut, West Hartford, USA

2 Rutgers University School of Social Work, New Brunswick, USA removed can die or experience further abuse. Separations between children and their primary caregivers can cause lasting disruptions in their social, emotional, and cognitive development (Bowlby 1969/1982, 1979, 1980) as well as be deeply traumatic to caregivers, especially when they are unwarranted. Once children have been removed from their families, the simple fact of the separation itself can make reunification difficult. Figuring out how to do decisionmaking well and fairly is just as highly fraught as the actual decision-making itself. Child welfare workers must make decisions with incomplete information, under time pressure, and often with competing mandates to privilege safety and maintain children in their home (Gambrill and Shlonsky 2000, 2001; Regher 2018). Further, decisions must be made at multiple points, each with their own potential for error and to undermine core values of equity. 
Not only are these decisions difficult to make, they are made about a large number of children. By age 18, approximately one-third of all children in the USA will have been the subject of a CPS investigation (Kim et al. 2017). Among them, only a small percentage will have had the allegations confirmed (approximately one in eight) (Wildeman et. al. 2014), with the majority (around 95\%) of children remaining in their homes at the conclusion of an investigation (DHHS 2020). Child maltreatment includes both abuse and neglect with neglect comprising approximately three-quarters of reports (DHHS 2019). Despite the large number of children involved with CPS over their lifetime, this experience is not equally shared across the population but rather it is, instead, bounded by race as well as class (Fong 2020, 2019). Black, Native American or Indigenous, and Latino families and families of low socioeconomic status have higher rates of child welfare involvement compared to their representation in the general population (e.g., Derezotes et al. 2004; Sedlak et al. 2010). Studies have demonstrated that economic hardship is causally associated with child maltreatment and child welfare involvement (Conrad-Hiebner and Byram 2020). Further, the distribution of economic hardship is heavily influenced by structural racism, resulting in proportionally more Black, Indigenous and Latino families experiencing economic hardship.

Given that both structural ${ }^{1}$ racism and economic hardship are relevant in causing and preventing maltreatment, we ask: How are those structural factors accounted for in risk assessment within child welfare systems? What are the consequences when these factors are left out of risk assessment design and procedures? In this conceptual paper, we analyze the most common tool for decision-making to determine the likelihood of future maltreatment in child welfare cases, the Structured Decision-Making Model's (SDM) risk assessment (RA). We deconstruct the RA to highlight how the RA focuses on individual behaviors and ignores structural factors, which in turn, obscures systematic risk and structural solutions for maltreatment. Specifically, we consider the ways in which risk factors selected for inclusion and those factors left out of the RA function to amplify racial disproportionalities in the child welfare system, obfuscating their connection to structurally created poverty. In doing so, we identify the mechanisms explaining Hirschman and Bosk's (2019) finding that actuarial-based risk assessments are unlikely to function as a vehicle for reducing racial disproportionality in child welfare, despite their explicit intention to do so.

\footnotetext{
1 We define systematic and structural racism as the intersecting effects of residential segregation, White political power, inequality in educational opportunities and economic opportunities, and policies and practices designed to restrict access based on race.
}

In this article, we first review the role of structural factors, particularly economic hardship, in child maltreatment. Next, we discuss the bias and differential risk explanations for racial disproportionality in the child welfare system, introducing structural risk as a new explanation for disproportionality that builds on both the bias and differential risk perspectives. Following this, we discuss the different and implicit interpretations of fairness embedded in each of these explanations, connecting their distinct logics to different policy and practice solutions. We then turn our attention to how the RA individualizes structural inequality in its assessment of maltreatment risk, identifying the consequences of inaccurate risk assessment. We conclude with a discussion of how child welfare risk assessment could be revisioned to better account for both structural and individual risk factors.

\section{Structural Factors and the U.S. Child Welfare System}

The majority of families involved in CPS in the USA experience some form of financial hardship, whether that is having an income below the poverty line or economic instability, such as lack of employment (Sedlak et al. 2010). In the last 20 years, research has indicated a causal role for structural economic factors in child maltreatment, particularly child neglect, and has identified the inverse relationship between a families' financial situation and the risk of official reports of maltreatment and of self-reported proxies for abusive or neglecting parenting behaviors (Berger 2004; Slack et al. 2004; Warren and Font 2015). When the number of economic resources that families have increases, child maltreatment decreases; conversely when economic resources decrease, child maltreatment increases (e.g., Berger 2017; Bullinger et al. 2019; Conrad-Hiebner and Byram 2020). These findings are consistent across studies of child support, the Earned Income Tax Credit (EITC), and in studies of changes in economic policy such as minimum wage increases, or macro-economic trends, such as unemployment, and economic uncertainty (Berger 2017; Raissian and Bullinger 2017; Schneider et al. 2017; Russell-Brown and DeCao 2018).

\section{Racial Disproportionality in Child Welfare}

Socioeconomic structural factors converge with structural racism, leading to the overrepresentation of Black, Indigenous, and Latino families and children in CPS relative to their percentages of the US population (CWIG 2016). This discrepancy is more pronounced and more consistent for children and families who are Black and Indigenous than it is for children and families who are Latino (Maguire-Jack 
et al. 2020). ${ }^{2}$ In contrast to these groups, White families are proportionally underrepresented in their CPS involvement. Research has also consistently noted under-representation of children who are Asian American or Pacific Islander (Maguire-Jack et al. 2020; AECF 2020).

While these trends are long-standing, issues of racial disproportionality and inequality have often been examined apart from socioeconomic conditions. Evidence of racial disproportionality were initially based on comparisons of the percentage of a given group in the CPS population with their percentage in the general population; with most of the focus on children in the foster care system rather than on other points of contact with the child welfare system (Fluke et al. 2003). This focus excluded the most common type of involvement with the child welfare system: reports and investigations. More recent studies correct this issue by primarily using administrative data with indicators of economic hardship (e.g., type of insurance or receipt of social welfare programs) to control for a family's risk of maltreatment and to identify the role of race or ethnicity at various points in the child welfare process (Drake et al. 2009; Putnam-Hornstein and Needell 2011; Kim and Drake 2018). These studies have generally found that after controlling for economic hardship, children who are Black or Latino were represented in proportion to estimated risk, with some studies finding children who are Latino are under-represented relative to their risk. A subset of this research has also found that at lower income levels, children who were White were represented at higher percentages than similarly situated families who were Black or Latino (Putnam-Hornstein and Needell 2011; Kim and Drake 2018). Studies using CPS-completed risk assessments to statistically control for maltreatment risk have identified that race/ethnicity is still significantly associated with CPS decisions at all points in the life of a case. In these studies, children who were Black received disproportionately worse outcomes (Rivaux et al. 2008; Miller 2008). Using a more comprehensive assessment of risk and family income from survey data, Font et al. (2012), contradict these findings, noting that children who were Black were represented in the child welfare system proportionate to their estimated risk.

\footnotetext{
2 Studies that include children and families who are Native American or Indigenous find similar disproportionate results as studies find for children and families who are Black. However, the geographic distribution and much smaller size of the population means that many studies do not include this population or have too small of a sample to analyze. Therefore, we may refer only to Black families to accurately represent the results of studies.
}

\section{Explanations for Racial Disproportionality and Racial Disparity}

The over-representation of any population in the child welfare system is problematic because of the punitive consequences that often accompany it. These specific negative experiences can vary from stigmatization, unwillingness to access social services, job loss, placement on central maltreatment registries, temporary loss of custody, and termination of parental rights. Further, despite focused efforts to reduce these differences, issues related to disproportionality and disparities continue to persist at every point in a child welfare case (reporting, substantiation, out-of-home placement, and reunification), challenging core values of a fair and equitable system. That the proportion of Black, Latino, Indigenous and White children involved in CPS is different relative to their proportion of the general population is inarguable. However, the reasons for this disproportionality remain highly contentious. There are two prominent explanations of this phenomenon, each with different internal logics that call for different solutions, and each with research findings supporting their diagnosis of the problem.

The first explanation, which we call, the 'bias' explanation contends that there is a similar amount of maltreatment across all families but because of racism, including implicit bias (i.e., bias that is unwilling or unconscious), families who are Black, Indigenous or Latino are reported, screened and become more involved in CPS at higher rates and/or the maltreatment of White children is overlooked (Fluke et al. 2011). Implicit in this explanation is the idea that Black, Indigenous, and Latino families do not deserve these more negative and severe outcomes because they are based on racialized interpretations of parental behavior. Here, fairness means that involvement with CPS (e.g., allegations) and all attendant decisions should only be associated with 'true' risk, which in turn, is understood not to be associated with race or ethnicity. Decision-making that is inconsistent with a family's predicted risk but rather uses other characteristics, such as race, to determine their outcome would be patently unfair. Studies that support the bias explanation have used a risk assessment similar to the SDM to adjust analyses for the risk of maltreatment, demonstrating the occurrence of biased decision-making based on race (Rivaux et al. 2008; Miller 2008). These studies conclude that more Black families are involved in the child welfare system than is warranted based on their identified risk level.

The second explanation, which we call the 'differential risk' explanation, contends that there are true underlying differences in the rates of maltreatment across demographic groups and that, while bias is likely present, racial disproportionality in CPS is primarily a reflection of these underlying differences (e.g., Drake et al. 2009). Quantitative studies 
examining the differential risk explanation have attempted to isolate the effect of race separately from the risks associated with financial hardship. These studies find that once variables for economic hardship and other case characteristics are included, the influence of race is attenuated or eliminated (Drake et al. 2009; Font et al. 2012; Putnam-Hornstein et al. 2013). Fairness in the differential risk explanation involves treating families in accordance with their risk of maltreatment, while acknowledging the inequality in life experiences that may heighten this risk. From this perspective, the decision-making associated with racial disproportionality is not inaccurate because the distribution in CPS by race/ethnicity is what would be expected based on the prevalence of risk factors across different demographic groups. These differentials are problematic because in a fair society they should not exist, but the disproportionality itself is not rooted in biased or inaccurate decision-making. Rather, child welfare workers likely need to take action in a disproportionate number of cases involving Black, Indigenous and Latino families to protect child safety.

We propose a third explanation, which we call the "structural risk" perspective. This perspective builds on both the bias and differential risk perspectives by explicitly considering the role that structural socioeconomic conditions play in shaping unequal CPS involvement while also acknowledging individual explicit and implicit bias. Specifically, this view understands disproportionality to emerge from the structural racism that shapes our current society, which in turns, results in the unequal distribution of resources and opportunities, and which elevates the maltreatment risk for some families. These inequalities are further amplified by biased decision-making that occurs throughout the system. This perspective contends that despite its structural origins, risk is primarily measured and addressed at the individual level. The structural risk explanation views a fair response to racial disproportionality as appropriately identifying all the places where maltreatment risk is situated. Accordingly, ecological assessment and intervention, in addition to individual assessment and intervention, is necessary to accurately identify and mitigate risk as is continued intervention related to individual bias.

\section{Implicit and Explicit Individual Bias as Cause of Racial and Ethnic Disproportionality in Child Protective Systems}

Since the 1980s, explanations of racism and persistent racial inequality have focused on individual explanations, situating unequal outcomes as a result of prejudiced attitudes and belief about the inferiority of Black and Brown people and the superiority of Whites that are expressed through discriminatory behaviors (Bonilla-Silva 1997; Golash-Boza
2016). In this framework, the sum total of these individual acts results in entrenched unequal outcomes for racial and ethnic minorities. This view aligns with the bias explanation. According to this diagnosis of racial disproportionality, if the actual prevalence of maltreatment is equivalent and the over-representation is from individual bias, then the two main locations of that bias are from those in the community reporting the maltreatment and from staff within the CPS making differential decisions based on demographic rather than case factors.

Children come to the attention of the CPS by being reported through a hotline by people in the community who observe a situation they feel constitutes maltreatment. These reporters may be mandated (e.g., teachers and doctors) to report perceived maltreatment or concerned community members. For biased reporting to be the primary source of racial disproportionality, reporters would have to consistently engage in explicit or implicitly biased reporting of children of color at higher rates and/or ignore or overlook the potential maltreatment of White children. Research supports this explanation, suggesting that racial minorities are overrepresented in allegations of maltreatment to CPS for all groups of reporters (Krase 2013).

Once a child is identified and reported, a series of decisions occurs within the CPS (Fig. 1), each of which constitutes another potential source of bias. The bias explanation suggests that child welfare workers, just like reporters, are making, often unknowingly, differential decisions (at one or multiple points) based on raced interpretations of families, resulting in a more punitive outcome for children and families who are Black, Indigenous, or Latino compared to similarly situated White children and families. One solution to this source of bias, then are tools that address bias in the screening process so that similar cases would have corresponding outcomes that are only based on the facts of the case rather than the demographics of a family, which might unconsciously influence decisions.

\section{Structural Racism and Poverty as Cause of Differential Risk}

In contrast to an individual bias perspective, sociologists of race view unequal outcomes to be rooted in structural factors (Bonilla-Silva 1997; Golash-Boza 2016). In this view, structural racism is systemic in nature, perpetuated through social institutions which create inequality even when individuals themselves do not hold explicitly racist beliefs or are acting in explicitly racist ways. Covertly segregationist policies (e.g., community funding of schools, redlining) function to engender racially discriminatory outcomes without being overtly racist in their intent (Ibid). Ideological commitments to a 'colorblind' meritocracy further create 
Fig. 1 Child welfare decisionmaking points in relation to the SDM

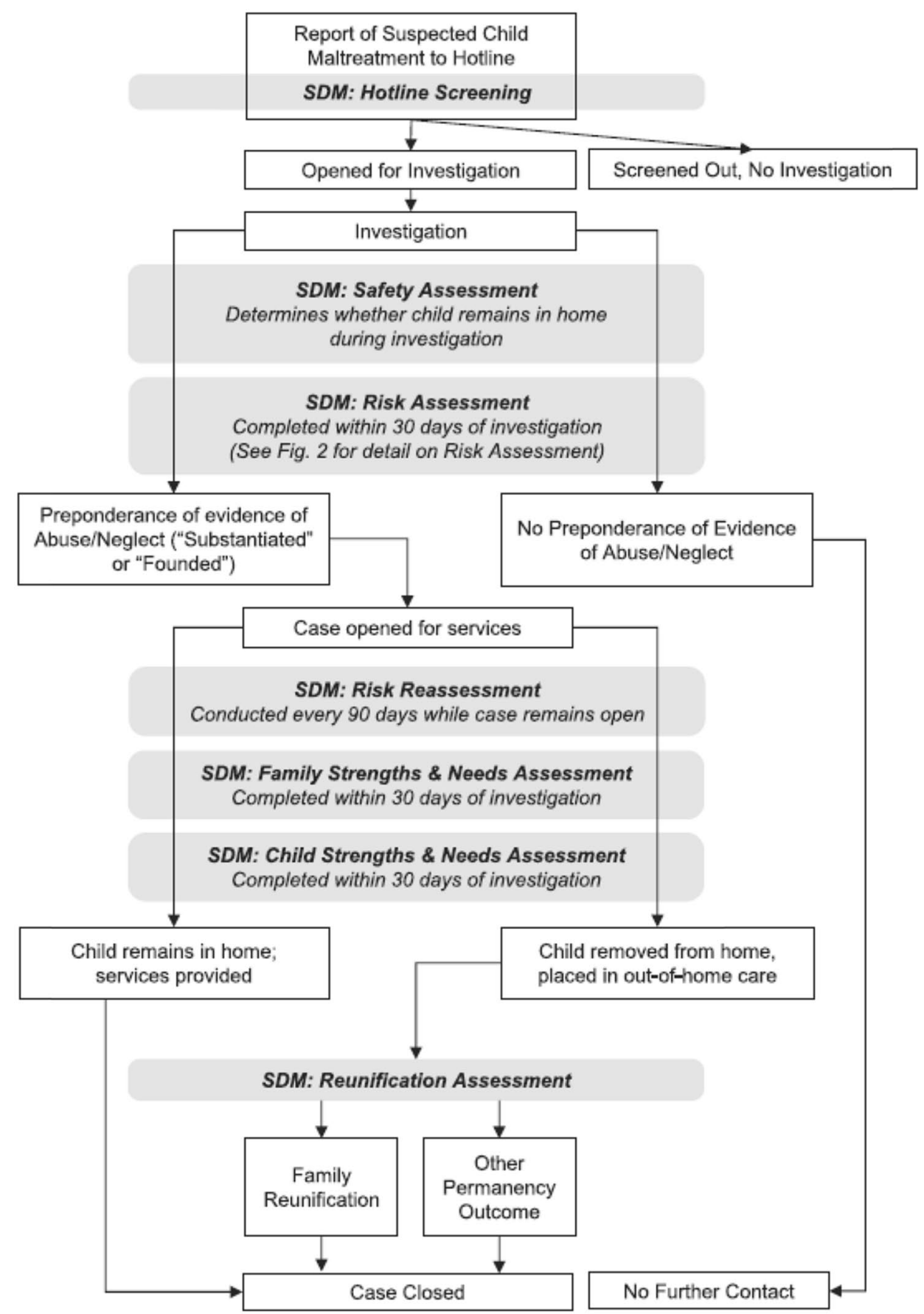

unequal outcomes as they obscure structural advantages for Whites and structural disadvantages for Blacks that need to be addressed for equality to be achieved (Bonilla-Silva 1997). This perspective aligns with explanations of racial disproportionality in the child welfare system as being located primarily in structural factors (Hirschman and Bosk 2019).

One outcome of implicitly racist social policies has been the intergenerational transmission of poverty or socioeconomic disadvantage. Decades of sociological research have mapped out the enduring nature of poverty, contradicting cherished cultural ideals of easily attainable class mobility within the USA (Corcoran 2001; Duncan et al. 1998; Putnam 2015; Sharkey 2008; Sharkey and Elwert 2011; Wagmiller and Adelman 2009). Explanations for why poverty is difficult to move out of draw on both structural, cultural, and biological descriptions ranging from inadequate resources, particularly educational ones, insufficient social support, social networks that do not promote access to job or educational opportunities (McEwaen and McEwen 2017), hopelessness, 
and environmental harm that alters brain structures and which limits advancement. Newer theories related to the intersection of cumulative disadvantage, toxic stress, and structural inequality highlight how early life adversity (much of which is structured by poverty), creates physiological changes that impact cognitive development and capacities for affective and behavioral regulation. Disrupted biological capacities intersect with inadequate provision of social goods (such as an adequate education, health care) to create challenges to economic advancement. Early adversity and cumulative disadvantage have been associated with lack of educational attainment, poor physical health in adulthood, and even early death (Shonkoff et al. 2012). McEwan and McEwen (2017) succinctly summarize these intersections as they relate to the intergenerational transmission of poverty:

A bio-social-ecological perspective (Ungar et al.2013) highlights multiple, interconnected systems: macrosystems of resource distribution; community, neighborhood, and institutional structures and their programmatic resources; relational networks of families, caregivers, friends, and neighbors; microsystems of interaction among children and between children and others in their social environments; and biological systems affected by and affecting these social systems. Because these systems connect with and depend upon one another, they are mutually reinforcing access or lack of access to resources at one level often leads to access to or lack of resources at another level (Miller et al. 2011).

Researchers have developed an extensive body of empirical research trying to disentangle the issue of poverty or financial hardship from maltreatment (Cancian et al. 2013; Conger et al. 1992; Conrad-Hiebner and Byram 2020; Drake et al. 2011; Feely et al. 2019; Marcal 2018; Maguire-Jack and Font 2017; Raissian 2015). These data consistently point to some causal role of financial hardship in maltreatment, most likely because it is difficult to constantly provide safe and consistent care for children with insufficient resources. While research has not determined all of the specific mediators between financial hardship and maltreatment, much of the research suggests that neglect (which accounts for threequarters of child welfare cases) is more strongly influenced by resources than abusive parenting practices (e.g., Berger et al. 2017; Feely et al. 2019; Raissian and Bullinger 2017).

Family Adjustment and Adaptation Response theory provides a theoretical framework for understanding the relationship between financial hardship and child neglect (Patterson 2002). This theory proposes that families have a certain amount of resources that primarily distill to time and money and they leverage these resources to deal with demands. When demands outweigh the resources to manage them, the family can tip into chaos, and, in the case of child neglect, be unable to provide safe and consistent care for their children (Feely et al. 2020). For families living in financially precarious situations, small increases in strains or decreases in resources can have significant effects. Some of the myriad ways that insufficient resources make it difficult to provide care include, but are not limited to, the inability to afford childcare, especially for shiftwork, unreliable transportation, living in housing where the building or neighborhood is unsafe resulting in a higher need for supervision, and insufficient money for food or clothing (Pelton 2015). The disproportionate number of families experiencing financial hardship in the child welfare system could look like biased representation because of the underlying historical structural racism of US society that has resulted in much larger numbers of families who are Black, Indigenous or Latino experiencing financial hardship. These families also are more likely to experience more financially precarious situations as their opportunities are continually suppressed by various forms of racism (Storer et al. 2020).

Debates about the cause of racial disproportionality in the child welfare system tend to frame the issue as dichotomous; either the child welfare system is racist and families do not present with differential risk or parents identified by the system are maltreating their children and therefore, racism is not the primary driver of the disproportionality. Our contention is that disproportionality in the child welfare system must be viewed from a sociological standpoint that characterizes disproportionality as emerging from a complex set of interactions between structural bias at the societal level and systemic bias within the child welfare system that then creates a greater risk for maltreatment among certain groups. Specifically, structural inequality shapes, and is shaped by, inadequate resources which in turn influences parent choices and behavior, and which is further amplified by biased decisions. We use the following inferences to propose a broader explanation of the emergence of racial disproportionality in CPS which we call the structural risk explanation:

1. The over-representation of children and families who are Black, Native American and Latino is a direct result of explicit structural and implicit individual bias; and,

2. That the largest source of this bias is the long-standing structural racism that has resulted in a greater proportion of families who are Black, Native American and Latino with insufficient resources to provide constant safe and consistent care for their children; and

3. As a result of these insufficient social and economic resources, that intermittent lapses in care do leave children at risk of harm, which results in parents being reported for maltreatment; and,

4. That as a field, while there has been a growing focus on the role of financial hardship, the role of structural racism leading to differential rates of poverty by race or 
ethnicity has been overlooked because individual bias by race and ethnicity is still prevalent and problematic; and

5. The way we typically assess and research maltreatment has severely limited our ability to locate the more significant role that structural racism and poverty plays; and

6. Complex interactions between social conditions and individual behavior can obscure the distal causes of maltreatment and focus interventions only on individuals (either child welfare workers or parents), rather than the underlying cause of maltreatment.

\section{Decisions, Decisions, Decisions}

While the roots of racial disproportionality and disparities in the child welfare system are multi-factorial and complex (Putnam-Hornstein et al. 2013; Pelton 2015; Font and Maguire-Jack 2015), organizational practices in child welfare have primarily focused on addressing racial disproportionality and disparities solely through efforts to implement policies and practices that will eliminate implicit or explicitly biased decisions that result in unequal outcomes for families and children who are Black, Indigenous or Latino. Actuarial-based tools are one such practice designed to address the historically low reliability and consistency of decision-making for cases with similar features (Baird and Wagner 2000). The understanding that subjectivity and implicit bias can creep into child welfare decision-making has then focused solutions on ensuring that individual assessments of each case are consistent and fair. These tools, as noted above, embrace an implicit bias view as the cause of racial disproportionality in the child welfare system (Hirschman and Bosk 2019).

At the same time that child welfare agencies have focused on introducing race neutral interventions, mesolevel practices that support 'colorblind' practices in organizations have received increasing attention as a vehicle for reproducing racist outcomes (Wooten and Coulette 2017; Ray and Purifoy 2019). The organizational tools and bureaucratic procedures that make up the routine administration of social policy and which may implicitly and inadvertently reinforce inequality have been largely outside the frame of organizational policy and decision-making across fields (Hirschman and Bosk 2019; Russell-Brown and DeCao 2018; Kalev et al. 2006). In child welfare, there is a need to examine the tools which shape decisions to understand their potential relationship to persistent disproportionality in this system, particularly from a perspective that holds structural racism and systematic bias to be a main driver of racial disproportionality in child welfare (Hirschman and Bosk 2019).

\section{The SDM Model}

The Structured Decision-Making Model (SDM) actuarial-based risk assessment (RA) is considered to be the 'gold standard' for solving issues related to the low reliability and bias inherent in child welfare risk assessment (Schwalbe 2008) and is currently used in the majority of the USA to frame child welfare decisions (Bosk 2018). Based on principles of actuarial science, The RA classifies cases into low, medium, intensive, and high risk for future maltreatment. Intended to be prognostic rather than diagnostic, the RA, according to its developers, improves "the effectiveness of the child welfare system by increasing the consistency and validity of decision-making" (CRC 1999). The goal is to standardize risk assessment to ensure that every family is evaluated utilizing the same process, and considering the same set of factors to maximize the chance that different workers assessing the same case will come to the same conclusion. This process was designed to ensure that only case level factors rather than demographic ones are considered for case decisions.

The RA was developed and refined by the National Council on Crime and Delinquency (NCCD) using validation studies to identify characteristics of families that indicate the potential for future maltreatment. Measures are determined using administrative child welfare data about the characteristics of families who have been investigated or substantiated for abuse and neglect and then link this information to case characteristics of families that have been re-referred for child maltreatment after an initial investigation and/or substantiation. Validation studies seek to establish the most influential risk factors for maltreatment, the combination of factors that are most likely to contribute to abuse or neglect, and the appropriate statistical weights and measures necessary to create a risk profile for families using this information. The goal of the RA is to more accurately classify cases for which future maltreatment is likely (Johnson and Bogie 2009).

While the content of the RA varies within each state or country that utilizes it, the basic structure is retained across them. Factors empirically related to maltreatment are assembled into two sets of inventories (one for neglect and one for abuse). Items are composed from a mix of demographic, historical, or current risks. These items contain both objective indicators (e.g., the number of the children in the home) and more subjective questions that require some interpretation from the worker (e.g., primary caretaker views incident less seriously than the department). Points are assigned to each item a caseworker endorses. At the completion of the assessment, the total points from the neglect inventory and the total points from the abuse inventory are calculated separately. The highest 


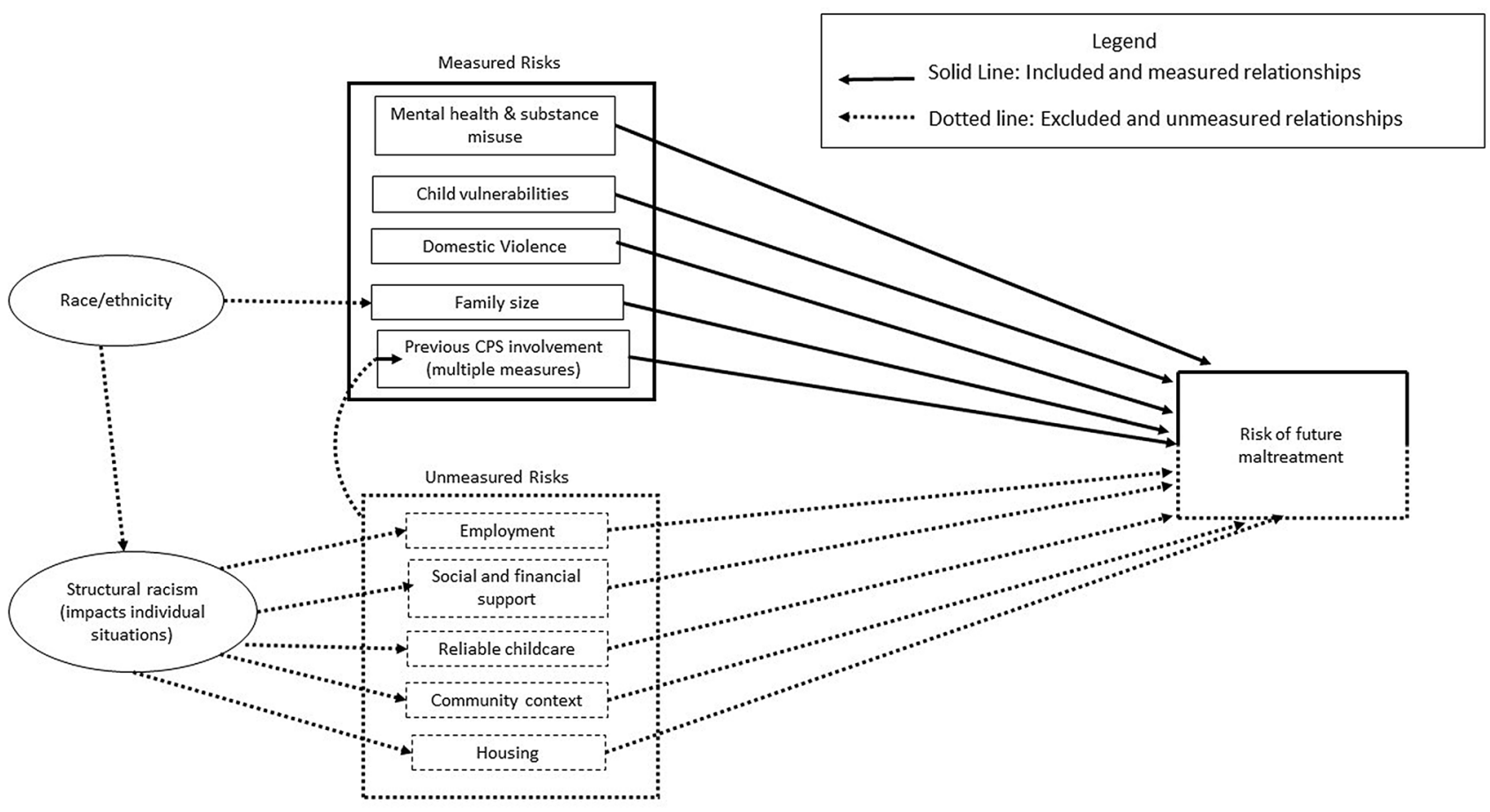

Fig. 2 The relationships between measured and unmeasured risk factors and risk of future maltreatment

number from either inventory reflects the final risk score, with higher numerical scores correlating with higher risk categories. A parent could score relatively low on the abuse inventory indicating low risk but relatively high on the neglect inventory, indicating high risk and the score for the parent would still result in a high risk designation, even if the allegation under investigation was for abuse.

The weight risk assessment scores carry in shaping CPS decision-making varies according to the policy and practice of each jurisdiction. The documented influence of risk scores range from minimal, functioning more as an after-thought or bureaucratic procedure, to determinative (Bosk 2018; Bosk 2019). In places where risk scores are highly influential, they may directly inform a number of different aspects of a case ranging from the number of contacts a family has with CPS, the level of services a family receives, placement on a publicly searchable central maltreatment registry, court intervention, and even child removal (Bosk 2018; Bosk 2019; Armstrong and Bosk 2020; Johnson and Bogie 2009) making them highly consequential in these settings.

Implicit in the construction of actuarial-based assessments are ideas about which aspects of child welfare cases should be considered over others and how case factors should be quantified. While these decisions are grounded in empirical data about risk factors for child maltreatment, they are also value laden (Bosk 2018; Bosk and Feely 2020; Hirschman and Bosk 2019). Figure 2 illustrates some of the choices that the developers of the RA made about which factors to include shown by solid lines, or exclude indicated by dotted lines. Unpacking these values is often overlooked and obscured by the more technical tasks of determining reliability and validity of assessments. Examining the intended and unintended consequences of what is left in and out of actuarial-based risk assessments is essential for understanding their impact on racial and ethnic disproportionality within the child welfare system.

\section{The SDM as a Means to Promote Equity in Decision-Making}

The NCCD purposefully constructs the RA as a 'color-blind' tool intended to reduce racial disproportionality in the child welfare system by removing racial considerations from the decision-making process for both the assessor and the assessed (Hirschman and Bosk 2019). As such, the RA does not include race as a factor in either the abuse or neglect inventory (Hirschman and Bosk 2019). By standardizing the content of the decisions, the RA attempts to suppress implicit bias from entering into case judgements. Equity, in this framework, is made possible within the tool by removing race and ethnicity from the conversation entirely so that only 'true' maltreatment risk is considered rather than factors that could bias decision-making. However, despite the intention to be 'color-blind,' many of the RA items implicitly pick up systemically driven inequalities that are likely at the heart of the long-standing crisis of racial disproportionality 
in child welfare (Hirschman and Bosk 2019). Specifically, leaving out both race and socioeconomic status as indicators means that other items then become proxies for these interrelated phenomena, also illustrated in Fig. 2.

\section{Weak Foundation, Poor Construction: Variable Choice and Implications}

The selection of variables included in the SDM embeds proxy measures for race/ethnicity and structural factors into its design, in particular the number of children. Four or more children involved in the allegation is a common factor on the risk assessments, yet families who are Black or Latino are more likely to have larger families. Twenty percent (20\%) of Latina mothers and $18 \%$ of mothers who are Black have four or more children compared to only $11 \%$ of White mothers (Pew Research Center 2015).

Structural socioeconomic factors are also embedded in or represented by proxy in the numerous variables about prior reports. These include any prior report, number of prior reports by allegation (abuse or neglect), and "previously referred for ongoing child protective services." Given the influence of structural socioeconomic factors on risk of maltreatment, these variables, which have some of the strongest correlations with adverse future outcomes, may serve as proxies for families who are adversely affected by the challenges related to low socioeconomic status. Functionally, families with low socioeconomic status are more likely to have multiple reports to CPS because structural barriers that are associated with neglect, particularly economic stability, have not been addressed. Figure 2 visually displays how systemic racism structures the likelihood that these proxies for financial hardship are more likely to affect Black, Indigenous, and Latino families. Further, Black, Indigenous, and Latino families are more likely to come under the scrutiny of officials that would make a child welfare report (Fong 2020), linking structural factors to this item.

Homelessness and housing that is unsafe may also function as proxies for both low socioeconomic status and race or ethnicity. Structural factors strongly influence who is likely to experience homelessness or severe housing instability. Over half of families who experienced homelessness and used shelters were families who were Black (UICH 2018). The distribution of who lives in areas of concentrated poverty, where the housing units are more likely to be unsafe, is also driven by structural racism with children who Black, Latino, American Indian or Alaska Native, or Asian/Pacific Islander six to nine times more likely than White children to live in areas of concentrated poverty (AECF 2012). These realities further unintentionally bake racial disparities that occur at the structural level into how risk is assessed at the individual level.
These issues are compounded by the facts that the RA includes variables that have a very weak correlation with the likelihood of future maltreatment and that its developers withhold from their published reports the results of the multivariable analyses that are used to determine which variables are included on the RA (e.g., Dankert and Johnson 2014; Johnson and Bogie 2009; NCCD 2015). Using publicly available SDM validation studies, the correlation between risk assessment items and the outcome, e.g., a subsequent report range, from 0.03 to 0.215 (Dankert and Johnson 2014; Johnson and Bogie 2009; NCCD 2015). A correlation represents the strength and direction of the relationship between two variables and values range from -1 to 1 . The closer a correlation is to 1 or -1 the stronger the relationship; values close to 0 represent a weak to meaningless association, less than 0.30 may be considered "negligible" (Mukaka 2012). Correlation is separate from statistical significance that is usually measured with a p-value. Particularly with a large sample, a value can be statistically significant without having a correlation that is strong enough to be substantively meaningful.

While the NCCD does not publish the regression results, other independent studies have found a weak, and, for some items, a nonsignificant, relationship between RA variables and the likelihood of a future maltreatment allegation and/or substantiation (Carlson et al. 2020). The weak relationship between the risk assessment variables and these outcomes is important to consider when examining the accuracy and validity of variables because a statistically significant relationship may not be consequential. In these cases, the real world connections between potential risks and the likelihood of future maltreatment are likely too small to accurately shape assessment and intervention. Therefore, the RA may be inaccurate about the risk of future maltreatment at the same time that it reifies racialized and classed notions of riskiness in its inclusion of these variables.

Another way in which proxy variables for race and class can adversely affect families is through the documented high false-positive rate for the tool. Specifically, a large number of families who will never have a subsequent maltreatment report score high on the RA (Loman and Siegel 2004). For example, in a validation study of the North Carolina RA, $70 \%$ of families identified as High or Intensive Risk did not have a subsequent report that merited an investigation, and $80 \%$ did not have a case opened within that 18 -month time period (Johnson and Bogie 2009). Risk assessment design inherently involves tradeoffs between sensitivity and specificity, which in turn, requires decisions to privilege either false-negatives or false-positives (Baird and Wagner 2000; Bosk 2018). In this case, specific thresholds for each risk category and the recommendations for the categories result in the more limited the precision of the tool, exacerbating issues related to the rate of high false-positives. 
The costs of a false-positive are more difficult to establish, document, and quantify, than the costs of false-negatives. This is particularly true for families who bear the consequences of incorrectly being categorized as high risk such as placement on the central registry for child maltreatment or child removal because these costs primarily are externalized to families and communities rather than born by the system (Bosk 2018). These costs are primarily externalized to families with low socioeconomic status and disproportionately on Black and Indigenous families. For example, even families who have had less severe consequences than having their child being removed due to a false-positive high score may be subjected to ongoing and frequent monitoring from CPS (Johnson and Bogie 2009). False-positives become true positives in future maltreatment investigations and decisions (Bosk 2018). As such, the negative consequences of falsepositives are more likely to remain unseen and unaddressed and these burdens are further unequally distributed across race and socioeconomic status.

The choices made during the RA design process result in a widely used tool that likely over-estimates some family's level of risk and under-identifies others. These over- and under-estimations likely originate from structural inequality but because they are assessed at an individual level, lead to the misdiagnosis of the sources of risk as within an individual's control (Hirschman and Bosk 2019). Leaving out socioeconomic and structural risk factors obfuscates the role of structural factors in supporting or preventing families from providing safe care for their children (Fig. 2).

\section{Discussion}

By focusing the conversation on individual and proximal risk factors rather than distal risk factors, actuarial-based risk assessments in child welfare reflect a field that frames the risk of future maltreatment entirely in individual rather than social terms. This process redistributes responsibility for risk that originates at a structural or a societal level and places it exclusively on the individual family or CPS workers to rectify (Simon 1998; Harcourt 2015). Harcourt (2015) refers to this process as a scrambling of social identities into individual practices that obscure our ability to understand how individual behaviors are shaped by social conditions. As a result, issues that have the potential for social and political mobilization such as the lack of appropriate childcare that is affordable or accessible are instead recast as individual decisions (e.g., the choice to leave a child unattended while a parent goes to work). Risky social conditions become instead understood as risky individuals making bad choices.

When child welfare risk assessments focus only on individual behaviors, the ways in which these choices are linked to social conditions become hard to see. Risk is nested and layered within systemically racist social structures such as redlining, lack of equal access to education, and lack of equal access to capital which then in turn creates racially situated economic conditions which lead to constrained options and consequently risky behaviors. Individually focused risk assessments only intervene at one step of this process, making it possible to solely consider individual parents as the problem without identifying the conditions that shape their choices or the serious economic constraints in which people must care for their children. The focus becomes on changing parental behaviors rather than changing the conditions that create their options and limits their choices. Similarly, CPS efforts at reducing bias have focused on implicit bias or diversity trainings for staff, situating the problem at the level of individual decision-makers rather than changing the options CPS workers have for supporting families. For example, if a family needs stable housing and help paying utilities for the children to be safe, these are not services that CPS (typically) can provide and the worker is left with few non-punitive options to ensure child safety.

COVID-19 has provided a grim illustration of the power of structural racism for shaping behavior, choices, and risk. People in the USA who are Black or Latino have had higher mortality rates from COVID-19 as a result of several different structural pathways (Pirtle 2020). Specifically, at a population level, Blacks and Latinos experience generally poorer health and life conditions, have higher rates of underlying health conditions that made the disease more deadly, are more likely to work in lower-wage jobs that were considered essential, live in communities where governments choose not to prioritize testing or personal protective equipment distribution, and were less likely to have healthcare that allowed them to access care early or to be tested before they were symptomatic.

These structural factors contributed to the higher mortality rate of people who are Black and Latino and none of them are a result of only individual level decisions. Solving racial disproportionality related to morbidity and mortality of COVID-19 therefore cannot only occur by targeting individual behavior change but instead must target the unequal conditions that make COVID-19 more likely to negatively impact the Black and Latino community disproportionately. In contrast to how CPS workers are often held responsible for the bias that exists in the system, the cause of these differential outcomes by race/ethnicity was not solely attributed to the patients or the medical professionals treating them. The robustness of the social determinants of health literature ensures that racial disparities, which could have otherwise been only blamed on the quality of care ${ }^{3}$ have not been

\footnotetext{
3 This is not to say that differential care has not been an issue in racially disparate outcomes for Blacks, Indigenous, and Latinos with COVID-19. There are multiple anecdotal accounts of physicians not taking their patients' symptoms seriously, suggestive of widespread individual explicit and implicit bias in medical care.
} 
overlooked in the national conversation about the cause of these differences. A similar conversation must take place in child welfare and must also be reflected in how families are assessed for risk and how these assessments are then linked to intervention.

Addressing the design limitations of the RA by including structural factors would only partially address the problems with the SDM RA. The difficulties with the implementation of the SDM are well-documented at the individual level (Bosk 2018, 2020; Font and Maguire-Jack 2015; Gillingham and Bromfield 2008; Gillingham and Humphreys 2009; Knoke and Trocme 2005) and at the organizational level (Bosk and Feely 2020). These identified problems range from inconsistent application of RA items to willful misapplication of the RA results. There is little reason to believe that these problems would have been avoided with a different set of questions on the risk assessment.

While we have detailed the problems with the exclusion of structural factors, particularly economic ones on the RA, it is apparent that alternative possibilities such as partial or inaccurate inclusion of structural variables, or misapplication of the data could result in inaccurate assessment. Without the clear and accepted connection between structural factors and structural racism, the "scrambling of societal and individual factors" would still have occurred but been more explicitly tied to race/ethnicity. That is, the field might have identified that economic factors were essential to maltreatment risk but in the absence of a clear structural theory, this association could easily have been explained as people who are Black, Indigenous, or Latino are more likely to make individual decisions that keep them poor. Therefore, a structural lens in child welfare risk assessment is critical to accurately identifying the necessary target of change. The relationship between the structural forces of poverty and maltreatment is a nuanced and multi-step theory, which requires a shift from attributing all maltreatment to individual pathology to recognizing that a majority of maltreatment is structurally shaped, which in turn, shapes individual choices and behavior. Such a theoretical realignment is unlikely to be best embodied through actuarial-based or predictive risk assessment models.

The structural risk perspective understands fairness to be intervening with structural risk that shapes the likelihood of maltreatment, while simultaneously responding to individual safety factors to protect children. This view contends that the disproportionate number of Black, Indigenous or Latino families who are also living in poverty or experiencing economic hardship is a direct result of structural racism rather than primarily influenced by individual decisions and choices. Rather than focusing on those constrained choices, improving structural supports such as providing more financial resources (e.g., income support, housing, childcare subsidies) would change the choices that families can make and that interventions that CPS workers have to offer. Separating families as a result of inadequate funding for these basic needs is a modern manifestation of debtor's prisons.

The costs of poor prediction are currently largely externalized to those families who are surveilled and who experience the negative repercussions of child welfare involvement. The child welfare system also loses when structural risks are ignored-families may be inaccurately assessed and resources poorly deployed. A society that is truly committed to addressing the problems of structural risk would develop a drastically different system for assessing risk and then, necessarily, different interventions for supporting families and protecting children. Federal standards for accurately assessing maltreatment risk should be established to prevent families from bearing the cost of unequal opportunity. These standards would also ensure that risk assessments do not privilege costs to organizations over costs to families in their design. Federal standards should include incentives for accuracy with penalties for poor estimates, such as increased state investments in areas where risk assessments were too inaccurate. Incentivizing organizational improvement and establishing accountability standards for risk assessment accuracy would encourage innovation and improved research in this area.

Just as the system has transmuted issues of structural inequality on to individual parents, so to, has the system transmuted structural issues of bias and disproportionality onto individual child welfare workers. While it is clear that issues of racial disproportionality in the child welfare system are multi-factorial, and that implicit bias at all decision-making points remains present, focusing the majority of solutions for racial disproportionality on eliminating implicit bias also absolves the child welfare system or larger US policy from addressing the social conditions that may make maltreatment more likely. It makes sense that child welfare policy would choose to target efforts at individuals whether it is child welfare workers or families rather than at the structure within which these individuals make decisions. This focus redirects intervention away from hard to obtain structural change that is outside the purview of the child welfare system to easier to implement individualized interventions with child welfare workers and families.

\section{Conclusion}

The most commonly used child welfare risk assessment does not include structural factors and leaving them out likely reflects a misdiagnosis of the racism causing disproportionality in the child welfare system. Further, this misdiagnosis has prevented effective solutions as families' needs go unmet while states focus on individual level assessments and interventions. There have been continued calls to focus on bias training as a 
way to address disproportionality by race or ethnicity, which are likely needed to intervene with individual bias that does exist in child welfare decision-making. At the same time, a greater appreciation of the structural origins of neglect is necessary to truly address racial disproportionality in the child welfare system. The current approach to assessment of risk is inaccurate, resulting in risks to both the child welfare system and to families. The field needs to convene a national board to radically revision how to assess risk of maltreatment that includes structural factors, accounts for the unequal distribution of risk and protective supports and develops a response that does not reify current structurally racist patterns.

Acknowledgements The authors would like to thank the Doris Duke Fellowship for the Promotion for Child Well-Being for introducing them to each other and encouraging collaborative scholarship and research.

\section{Compliance with ethical standards}

Conflict of interest The authors have no conflict of interest to disclose.

\section{References}

Annie E. Casey Foundation. (2020). Annie E. Casey Foundation, Kids Count Data Center. https://datacenter.kidscount.org/updates/ show/264-us-foster-care-population-by-raceand-ethnicity.

Annie E. Casey Foundation (AECF). (2012). Kids Count Data Snapshot on high-poverty communities. http://www.aecf.org $/ \mathrm{m} /$ resourcedoc/AECFChildrenLivingInHighPovertyCommunities2012-Full.pdf.

Baird, C., \& Wagner, D. (2000). The relative validity of actuarial and consensus based risk assessment systems. Children and Youth Services Review, 22, 839-871.

Berger, L. M. (2004). Income, family structure, and child maltreatment risk. Children and Youth Services Review, 26(8), 725-748.

Berger, L. M., Font, S. A., Slack, K. S., \& Waldfogel, J. (2017). Income and child maltreatment in unmarried families: Evidence from the earned income tax credit. Review of Economics of the Household. https://doi.org/10.1007/s11150-016-9346-9.

Bonilla-Silva, E. (1997). Rethinking racism: Toward a structural interpretation. American Sociological Review, 50, 465-480.

Bosk, E. A. (2018). What counts? quantification, worker judgment, and divergence in child welfare decision making. Human Service Organizations: Management, Leadership \& Governance, 42(2), 205-224.

Bosk, E. A. (2020). Iron cage or paper cage? The interplay of worker characteristics and organizational policy in shaping unequal responses to a standardized decision-making tool. Social Problems, 67(4), 654-676.

Bosk, E., \& Feely, M. (2020). The Goldilocks Problem: Tensions between Actuarially Based and Clinical Judgment in Child Welfare Decision Making. Social Service Review, 94(4), 659692.https://doi.org/10.1086/712060

Bowlby, J. (1969/1982). Attachment and Loss: Attachment (Vol. 1). New York: Basic Books.

Bowlby, J. (1979). The making and breaking of affectional bonds. New York: Basic Books.

Bowlby, J. (1980). Attachment and Loss: Loss Sadness and Depression (Vol. 3). New York: Basic Books.
Bullinger, L. R., Feely, M., Raissian, K. M., \& Schneider, W. (2019). Heed neglect, disrupt child maltreatment: A call to action for researchers. International Journal on Child Maltreatment: Research, Policy and Practice, 1-12.

Carlson, P. M., Feely, M., Kurz, B., Lin, H. J., Ives, M., Pierce, J., ... \& Nilson, K. (2020). Connecticut's family assessment response system. Journal of Public Child Welfare, 1-24

Cancian, M., Yang, M. Y., \& Slack, K. S. (2013). The effect of additional child support income on the risk of child maltreatment. Social Service Review, 87(3), 417-437

Conger, R. D., Conger, K. J., Elder, G. H., Lorenz, F. O., Simons, R. L., Whitbeck, L. B., ... Simons, R. L. (1992). A family process model of economic hardship and adjustment of early adolescent boys. Child Development, 63(3), 526-541

Child Welfare Information Gateway. (2016). Racial disproportionality and disparity in child welfare. Washington, DC: U.S. Department of Health and Human Services, Children's Bureau.

Conrad-Hiebner, A., \& Byram, E. (2020). The temporal impact of economic insecurity on child maltreatment: A systematic review. Trauma, Violence, \& Abuse, 21(1), 157-178.

Corcoran, M. (2001). Mobility, persistence, and the consequences of poverty for children: Child and adult outcomes. In S. H. Danziger \& R. H. Haveman (Eds.), Understanding poverty (pp. 127-161). New York: Russell Sage Found.

CRC. (1999). The Improvement of Child Protective Servies with Structured Decision Making: The CRC Model. In NCCD (Ed.).

Dankert, E.W. \& Johnson, K. (2014). Risk assessment validation: A prospective study. California Department of Social Services, Children and Family Services Division, Children's Research Center, National Council on Crime and Delinquency.

Derezotes, D. M., Testa, M. F., \& Poertner, J. (2004). Race matters: Examining the overrepresentation of African Americans in the child welfare system. Washington DC: Child Welfare League of America.

Drake, B., Jolley, J. M., Lanier, P., Fluke, J., Barth, R. P., \& JonsonReid, M. (2011). Racial bias in child protection? A comparison of competing explanations using national data. Pediatrics, 127(3), 471-478.

Drake, B., Lee, S. M., \& Jonson-Reid, M. (2009). Race and child maltreatment reporting: Are Blacks overrepresented? Children and Youth Services Review, 31(3), 309-316.

Duncan, G. J., Yeung, W. J., Brooks-Gunn, J., \& Smith, J. R. (1998). How much does childhood poverty affect the life chances of children? American Sociological Review, 63, 406-412.

Feely, M., Seay, K. D., \& Loomis, A. M. (2019). Harsh physical punishment as a mediator between income, re-reports and out-ofhome placement in a child protective services-involved population. Children and Youth Services Review, 103, 70-78.

Feely, M., Raissian, K., Schneider, W., Bullinger, L. (2020). The social welfare policy landscape and child protective services: Opportunities for and barriers to creating system synergy. Annals of the American Academy of Political and Social Sciences. 692(11):140-161

Fluke, J., Harden, B. J., Jenkins, M., \& Ruehrdanz, A. (2011). Research synthesis on child welfare: Disproportionality and disparities. Disparities and Disproportionality in Child Welfare,

Fluke, J. D., Yuan, Y. Y. T., Hedderson, J., \& Curtis, P. A. (2003). Disproportionate representation of race and ethnicity in child maltreatment: Investigation and victimization. Children and Youth Services Review.

Fong, K. (2019). Concealment and constraint: Child protective services fears and poor mothers' institutional engagement. Social Forces, 97(4), 1785-1810.

Fong, K. (2020). Getting eyes in the home: child protective services investigations and state surveillance of family life. American Sociological Review, 85(4), 610-638. 
Font, S. A., Berger, L. M., \& Slack, K. S. (2012). Examining racial disproportionality in child protective services case decisions. Children and Youth Services Review, 34(11), 2188-2200.

Font, S. A., \& Maguire-Jack, K. (2015). Decision-making in child protective services: Influences at multiple levels of the social ecology. Child Abuse \& Neglect, 47, 70-82.

Golash-Boza, T. (2016). A critical and comprehensive sociological theory of race and racism. Sociology of Race and Ethnicity, $2(2), 129-141$.

Gambrill, E., \& Shlonsky, A. (2000). Risk Assessment in context. Children and Youth Services Review, 22(11-12), 813-837.

Gambrill, E., \& Shlonsky, A. (2001). The need for comprehensive risk management systems in child welfare. Children and Youth Services Review, 23(1), 79-107.

Gillingham, P., \& Bromfield, L. (2008). Child protection, risk assessment and blame ideology. Children Australia, 33(1), 18-24.

Gillingham, P., \& Humphreys, C. (2009). Child protection practitioners and decision-making tools: Observations and reflections from the front line. British Journal of Social Work, 40(8), 2598-2616.

Harcourt, B. (2015). Risk as a proxy for race: The dangers of risk assessment. Federal Sentencing Reporter, 27(4), 237-243.

Hirschman, D., \& Bosk, E. A. (2019). Standardizing biases: Selection devices and the quantification of Race. Sociology of Race and Ethnicity. https://doi.org/10.1177/2332649219844797.

Johnson, K., Bogie, A. (2009). Risk assessment validation: A prospective study. Children's Research Center, National Council on Crime and Delinquency. Madison, WI.

Kalev, A., Dobbin, F., \& Kelly, E. (2006). Best practices or best guesses? Assessing the efficacy of corporate affirmative action and diversity policies. American Sociological Review, 71(4), 589-661.

Kim, H., \& Drake, B. (2018). Child maltreatment risk as a function of poverty and race/ethnicity in the USA. International Journal of Epidemiology, 47(3), 780-787. https://doi.org/10.1093/ije/dyx28 0 .

Kim, H., Wildeman, C., Jonson-Reid, M., \& Drake, B. (2017). Lifetime prevalence of investigating child maltreatment among US children. American journal of public health, 107(2), 274-280.

Knoke, D., \& Trocme, N. (2005). Reviewing the evidence on assessing risk for child abuse and neglect. Brief Treatment and Crisis Intervention, 5(3), 310-327. https://doi.org/10.1093/brief-treat ment/mhi024.

Krase, K. S. (2013). Differences in racially disproportionate reporting of child maltreatment across report sources. Journal of Public Child Welfare, 7(4), 351-369.

Loman, L.A. \& Siegel, G.L. (2004). An evaluation of the Minnesota SDM Family Risk Assessment, conducted for the Minnesota Department of Human Services. A report of the Institute of Applied Research. St. Louis, MO

Maguire-Jack, K., \& Font, S. A. (2017). Community and individual risk factors for physical child abuse and child neglect: Variations by poverty status. Child Maltreatment, 22(3), 215-226. https:// doi.org/10.1177/1077559517711806.

Maguire-Jack, K., Font, S. A., \& Dillard, R. (2020). Child protective services decision-making: The role of children's race and county factors. American journal of orthopsychiatry, 90(1), 48.

Marcal, K. E. (2018). The impact of housing instability on child maltreatment: A causal investigation. Journal of Family Social Work, 21(4-5), 331-347. https://doi.org/10.1080/10522158.2018.14695 63.

McEwen, C. A., \& McEwen, B. S. (2017). Social structure, adversity, toxic stress, and intergenerational poverty: An early childhood model. Annual Review of Sociology, 43, 445-472.

Miller, M. G. (2008). Racial disproportionality in Washington State's child welfare system. Olympia, WA: Washington State Institute for Public Policy.
Miller, G. E., Chen, E., \& Parker, K. J. (2011). Psychological stress in childhood and susceptibility to the chronic diseases of aging: Moving toward a model of behavioral and biological mechanisms. Psychological Bulletin, 137, 959-997.

Mukaka, M. M. (2012). A guide to appropriate use of correlation coefficient in medical research. Malawi Medical Journal, 24(3), $69-71$.

National Council on Crime and Delinquency (NCCD). (2015). Preliminary Risk Assessment Fit Analysis of the SDM® Family Risk Assessment Prepared for Texas Department of Family and Protective Services. NCCD, Children's Research Center.

Patterson, J. M. (2002). Integrating family resilience and family stress theory. Journal of Marriage and Family, 64(2), 349-360.

Pelton, L. H. (2015). The continuing role of material factors in child maltreatment and placement. Child Abuse \& Neglect, 41, 30-39.

Pew Research Center. (2015). Childlessness falls, family size grows among highly educated women. Washington, DC: May

Pirtle, W. N. L. (2020). Racial capitalism: a fundamental cause of novel coronavirus (COVID-19) pandemic inequities in the United States. Health Education \& Behavior

Putnam, R. B. (2015). Our kids: The American Dream in Crisis. New York: Simon \& Schuster.

Putnam-Hornstein, E., Needell, B., King, B., \& Johnson-Motoyama, M. (2013). Racial and ethnic disparities: A population-based examination of risk factors for involvement with child protective services. Child Abuse \& Neglect, 37, 33-46.

Putnam-Hornstein, E., \& Needell, B. (2011). Predictors of child protective service contact between birth and age five: An examination of California's 2002 birth cohort. Children and Youth Services Review, 33(8), 1337-1344.

Raissian, K. M. (2015). Does unemployment affect child abuse rates? Evidence from New York State. Child Abuse \& Neglect, 48, 1-12.

Raissian, K. M., \& Bullinger, L. R. (2017). Money matters: Does the minimum wage affect child maltreatment rates? Children and Youth Services Review, 72, 60-70.

Ray, V., \& Purifoy, D. (2019). The Colorblind Organization', Race, Organizations, and the Organizing Process (Research in the Sociology of Organizations, Volume 60).

Regehr, C. (2018). Stress, trauma, and decision-making for social workers. Columbia University Press, New York.

Rivaux, S. L., James, J., Wittenstrom, K., Baumann, D., Sheets, J., Henry, J., \& Jeffries, V. (2008). The intersection of race, poverty, and risk: Understanding the decision to provide services to clients and to remove children. Child Welfare, 87(2), 2-7.

Russell-Brown, D., \& De Cao, E. (2018). The impact of unemployment on child maltreatment in the United States (No. 2018-04). ISER Working Paper Series.

Sedlak, A. J., Mettenburg, J., Basena, M., Peta, I., McPherson, K., \& Greene, A. (2010). Fourth National Incidence Study of Child Abuse and Neglect (NIS-4). Washington, DC: US Department of Health and Human Services, 9, 2010.

Sharkey, P. (2008). The intergenerational transmission of context. American Journal of Sociology, 113, 931-969.

Sharkey, P., \& Elwert, F. (2011). The legacy of disadvantage: Multigenerational neighborhood effects on cognitive ability. American Journal of Sociology, 116, 1934-1981.

Shonkoff, J. P., Garner, A. S., Siegel, B. S., Dobbins, M. I., Earls, M. F., McGuinn, L., ... \& Committee on Early Childhood, Adoption, and Dependent Care. (2012). The lifelong effects of early childhood adversity and toxic stress. Pediatrics, 129(1), e232-e246

Schwalbe, C. S. (2008). Strengthening the integration of actuarial risk assessment with clinical judgment in an evidence based practice framework. Children and Youth Services Review, 30(12), $1458-1464$ 
Schneider, W., Waldfogel, J., \& Brooks-Gunn, J. (2017). The Great Recession and risk for child abuse and neglect. Children and Youth Services Review, 72, 71-81.

Slack, K. S., Holl, J. L., McDaniel, M., Yoo, J., \& Bolger, K. (2004). Understanding the risks of child neglect: An exploration of poverty and parenting characteristics. Child maltreatment, 9(4), 395-408

Storer, A., Schneider, D., \& Harknett, K. (2020). What explains racial/ ethnic inequality in job quality in the service sector?. American Sociological Review, 85(4), 537-572.

US Interagency Council on Homelessness. (2018). Homelessness in America: Focus on Families With Children.

Ungar, M. (2013). Resilience, trauma, context, and culture. Trauma, Violence, \& Abuse, 14(3), 255-266.

U.S. Department of Health \& Human Services, Administration for Children and Families, Administration on Children, Youth and Families, Children's Bureau. (2019). Child Maltreatment 2017. Available from https://www.acf.hhs.gov/cb/research-data-technology/ statistics-research/child-maltreatment.

U.S. Department of Health \& Human Services, Administration for Children and Families, Administration on Children, Youth and
Families, Children's Bureau. (2020). Child Maltreatment 2018. Available from https://www.acf.hhs.gov/cb/research-data-technology /statistics-research/child-maltreatment.

Wagmiller, R. L., Jr., \& Adelman, R. M. (2009). Childhood and intergenerational poverty: The long-term consequences of growing up poor. New York: National Center for Children in Poverty.

Warren, E. J., \& Font, S. A. (2015). Housing insecurity, maternal stress, and child maltreatment: An application of the family stress model. Social Service Review, 89(1), 9-39.

Wildeman, C., Emanuel, N., Leventhal, J. M., Putnam-Hornstein, E., Waldfogel, J., \& Lee, H. (2014). The prevalence of confirmed maltreatment among US children, 2004 to 2011. JAMA pediatrics, 168(8), 706-713.

Wooten, M., \& Couloute, L. (2017). The production of racial inequality within and among organizations. Sociology Compass, 11(1), 1-10.

Publisher's Note Springer Nature remains neutral with regard to jurisdictional claims in published maps and institutional affiliations. 